\title{
Presentación de Otros temas del Número 82
}

\section{Presentation of Other Themes from Number 82}

\begin{abstract}
Luis Montaño Hirose*
Universidad Autónoma Metropolitana, Iztapalapa orCIDः http://orcid.org/o0oo-0003-0076-I777 DoI: http://dx.doi.org/I0.28928/revistaiztapalapa/822017/pot/montanohirosel
\end{abstract}

El lector encontrará en la sección de Otros temas del número 82 de Iztapalapa. Revista de Ciencias Sociales y Humanidades tres artículos que se adentran en el estudio de diversos aspectos de nuestra vida social contemporánea - la nueva expresión artística callejera, el vínculo individuo-muerte-significado y la economía mundial-, los cuales son complementados por dos reseñas de libros que abordan temas relevantes para una mejor comprensión de preocupaciones esenciales de nuestro tiempo - la ciudad y la justicia-. Los autores realizan sus propuestas desde diversos campos disciplinarios - sociología, ciencia cognitiva, economía, teoría literaria y filosofía - y nos ayudan a lograr un mejor entendimiento de la compleja trama de nuestra realidad cotidiana. En este esfuerzo, autores centrales como Bourdieu, Varela, Marx, Onetti y Habermas son retomados mediante reelaboraciones teóricas para lograr una mejor comprensión de los fenómenos estudiados.

*1mh52@prodigy.net.mx 
El artículo "Nuevas formas de street art: una aproximación desde la teoría de los campos", de Melina Amao Ceniceros, investigadora de El Colegio de la Frontera Norte, tiene como objetivo estudiar las formas actuales de producción artística urbana en la ciudad de Tijuana a partir de la teoría del campo social de Pierre Bourdieu. La autora enfatiza la disputa por el campo desde una perspectiva tanto material como simbólica. En el trabajo se indaga sobre su transformación debido a la incorporación de nuevos actores que cuestionan su sentido social y estético. $\mathrm{Al}$ campo establecido de los grafiteros, valorados por expresar una identidad popular, por el riesgo asumido al actuar en la clandestinidad, por cuestionar el statuo quo social y contravenir las visiones convencionales de la estética, se contrapone desde hace cerca de una década una nueva visión del arte callejero, el de los jóvenes profesionistas provenientes de la arquitectura, el diseño, las artes plásticas y la publicidad, capaces de negociar permisos para plasmar sus obras con contenidos estéticos más elaborados pero menos comprometidos socialmente.

Por su parte, Tom Froese, de la Universidad Nacional Autónoma de México, aborda, en su ensayo "La vida es preciosa por ser precaria: Individualidad, mortalidad y el significado", un tema poco estudiado en nuestro medio: el de la relación entre vida y mente. En él realiza una crítica a las teorías convencionales del computacionalismo mediante la introducción del concepto de sentido, basado en las nociones de individualidad y mortalidad. La corriente del computacionalismo se sustenta en la perspectiva cibernética de la autoproducción de los sistemas complejos y en la comparación, con fines unificadores, entre la mente y la computadora; considera a la primera como un mecanismo procesador de información, similar al de una computadora digital. El autor reformula algunos supuestos de la ciencia cognitiva para realizar una crítica a dicha posición teórica bajo el argumento de que la individualidad, la muerte y el significado están íntimamente imbricados, lo que permite el reconocimiento de aquello que es valioso para un sistema vivo. La muerte refuerza el sentido de individualidad y le otorga a la vida el estatus de precariedad, haciéndola altamente significativa y, por lo tanto, preciosa. Los sistemas físicos, por su parte, tienen una gran dificultad para definir el concepto de individualidad ya que la muerte, como la vida, en dichos sistemas es considerada virtual al asumirse como estructuras de información remplazables, generando con ello esquemas simples de significado. Las asociaciones de la entropía con la muerte, del significado con la información pertinente y de la individualidad con la agencia resultan insuficientes para construir un puente entre los sistemas biológico y físico. 
En el tercer artículo,"El análisis marxista de la economía mundial y los estudios sobre el desarrollo", Isaac Enríquez Pérez, de la Universidad Nacional Autónoma de México, presenta una introducción a los principales conceptos marxistas y aduce que esta perspectiva teórica-metodológica constituye un marco analítico riguroso para comprender los procesos económicos generales, incluido el mundial. Señala que si bien esa no era la intención de Marx, este estableció las bases para llevar a cabo dicha tarea. El autor parte de la premisa de que la economía mundial es una realidad sistémica no descifrable mediante la sumatoria de las economías nacionales y que es en este marco que debe estudiarse la relación complementaria y contradictoria de desarrollo/subdesarrollo. Con espíritu crítico, señala algunas limitaciones teóricas que deben subsanarse para alcanzar un mayor nivel de inteligibilidad de los complejos fenómenos sociales estudiados por el marxismo. De entre ellas, cabe destacar su concepción lineal de la historia, su anclaje en una visión científica mecánica, su alto determinismo social y económico sobre el individuo, su falta de atención a la relación de la sociedad con la naturaleza, su visión esquemática del Estado como simple prolongación del poder capitalista y su perspectiva política que reduce el fenómeno del poder a la lucha entre dos clases sociales.

Otros temas se complementa con las reseñas de dos libros, escritos por profesores investigadores de la Universidad Autónoma Metropolitana, Unidad Iztapalapa. El primero de ellos se intitula Juan Carlos Onetti: Caprichos con ciudades, de Rocío Antúnez Olivera. El libro fue publicado por esta casa de estudios, en coedición con Gedisa. La reseña ha sido elaborada por Marina Martínez Andrade, quien menciona, "entre sus múltiples aciertos, dos fundamentales: por un lado se enmarca en una nueva forma de trabajar el espacio urbano en obras narrativas de la literatura hispanoamericana y, por otro, aplica tan novedoso enfoque al análisis de algunos de los primeros cuentos y novelas del escritor uruguayo Juan Carlos Onetti, autor de verdaderas obras maestras en los géneros narrativos cuento, novela y noveleta”.

El segundo libro,"La Ratio Iuris en la era de la Posmetafísica. Jürgen Habermas y la nueva fundamentación teórico-discursiva de la filosofía del derecho", pertenece a Francisco Castillejos y resulta de gran relevancia para la comprensión del papel del derecho en la sociedad moderna. Este ha sido publicado por la Universidad Autónoma Metropolitana, Unidad Iztapalapa, en convenio con Editorial Lo Blanch. La obra se ubica en la filosofía del derecho y sustenta su análisis en los escritos de Habermas. Uno de los méritos centrales de esta obra, de acuerdo con Alejandro Nava Tovar, autor de una minuciosa reseña, es que conjunta de manera equilibrada el derecho y la filosofía. El libro parte de las primeras concepciones del 
derecho romano, en tanto teoría y praxis, y establece una periodización que permite el análisis de las aportaciones habermasianas al derecho, transitando del derecho burgués y natural a la razón comunicativa, el derecho cosmopolita, hasta arribar a la teoría discursiva. Este recorrido, señala Alejandro Nava, está acompañado de un diálogo fructífero con sociólogos, filósofos y juristas, lo que le otorga a la obra un lugar especial en la literatura latinoamericana especializada. 